\title{
The In Vivo Wear Resistance of 12 Composite Resins
}

\author{
Brien R. Lang, DDS, MS, * Thomas J. Bloem, DDS, MS, †John M. Powers, PhD + \\ and Rui-Feng Wang, $B S^{\S}$
}

\begin{abstract}
Purpose: The in vivo wear resistance of 12 composite resins were compared with an amalgam control using the Latin Square experimental design. Sixteen edentulous patients wearing specially designed complete dentures formed the experimental population.

Materials and Methods: The Michigan Computer Graphics Measurement System was used to digitize the surface of the control and composite resin samples before and after 3-month test periods to obtain wear data. The 12 composite resins selected for this investigation based on their published composite classification types were seven fine particle composites, three blends, and two microfilled composite resins. The Latin Square experimental design was found to be valid with the factor of material being statistically different at the $5 \%$ level of significance. Wear was computed as volume loss $\left(\mathrm{mm}^{3} / \mathrm{mm}^{2}\right)$, and all of the composites studied had more wear than the amalgam control $(P=.001)$.

Results: After 3 months, the mean (error) of wear of the amalgam was $0.028(0.006)$. Means (error) of wear for the 12 composites were ranked from most to least wear by mean wear volume loss.

Conclusion: The absence of any relationship between mean wear volume loss and the volume percentage filler was confirmed by the correlation coefficient $r=-0.158$.

J Prosthod 1:2-10. Copyright $\odot 1992$ by the American College of Prosthodontists.
\end{abstract}

INDEX WORDS: composites, filler particles, in vivo wear

$\mathrm{T}$ he clinical evaluation of composite resin wear is one of the most challenging subjects in dental materials research. Such clinical trials are expensive, involve considerable time, and wear is difficult to measure because wear is so complex..$^{1-3}$ A number of measurement methods have been used in composite resin wear studies, including examiners' assessments using written criteria (U.S. Public Health Service criteria), ${ }^{4,5}$ mirror and explorer evaluations against dimensional standards, ${ }^{6-8}$ studies of in vivo replicas using scanning electron microscopy (SFM), ${ }^{9-12} \mathrm{com}-$ puterized image analysis, ${ }^{13,14}$ and/or two- and three-

* Professor and Chair, Department of Prasthodontics, the University of Michigam, School of Dentisty, Ann Avbo, MI.

†Assislant Professor, Department of Prosthodontics, the University' of Michigan, School of Dentistri, Ann Arbor, MI.

$\ddagger$ Professer and Chair, Department of Oral Biomaterials, University of Texas Health Seience Center al Houston, TX.

\$Research Associate I, Prosthodontic Research Laboratory, the University of Michigan, School of Dentistry, Ann Arbor, MI.

This study was supported by research grant $D E 06720$ from the National Institute of Dental Research, National Insitules of Heallh, Bethesda, MD.

Address reprint requests to: Brien R. Lang, DDS, MS, Department of Prosthadontics, School of Dentistr; University of Michigan, 1011 North University, Ann Arbor, MI 48109-1078.

Cupyright $\odot 1992$ by the American College of Prosthodontists $1059-941 \times / 92 / 0101-0001 \$ 5.00 / 0$ dimensional surface measurement systems. ${ }^{15-21}$ To date, no single method has proven superior. Even though difficult, wear data from clinical testing of composites are essential to the clinicians who must make judgments daily in their clinical practices, in material selection for restoration placement.

\section{Materials and Methods}

The clinical measurement of wear involves more than one factor because of the complex naturc of these materials and the clinical cnvironment itself. In such studies, a factorial design as shown in Fig 1, has usually been the experimental method selected. However, this design becomes extremely difficult because of the requirement of repeated measures to arrive at a mean for the analysis of variance (ANOVA), and the time needed to gather all the data to complete the design may limit the use of this method by investigators.

The Latin Square experimental design ${ }^{22-25}$ that selects only a fraction of the full factorial experiment has becn uscd successfully by the authors in similar clinical studies. ${ }^{26}$ In the Latin Square, only a fraction of the full factorial design is selected to provide a balance between the number of factors and their 
Figure 1. Sixty-four observations are required to examine the three factors of $\mathrm{T}=$ Tooth, $\mathbf{M}=$ Material, and $\mathrm{R}=3-$ Month Test Period. The highlighted areas represent a fraction of the experimental plan when the Latin Square design is selected.

\begin{tabular}{|c|c|c|c|c|c|c|c|c|c|c|c|}
\hline$T$ & $\mathbf{M}$ & $\mathbf{P}$ & $T$ & $\mathbf{M}$ & $\mathbf{P}$ & $T$ & $\mathbf{M}$ & $\mathbf{P}$ & $T$ & $\mathbf{M}$ & $\mathbf{P}$ \\
\hline 18 & A & 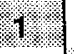 & 19 & A & 1 & 30 & A & 1 & 31 & A & 1 \\
\hline 18 & $A$ & 2 & 1.9 & A & 2 & 30 & A & 2 & 31 & t & 2 \\
\hline 18 & $A$ & 3 & 19 & $A$ & 3 & 30 & 4 & 3 & 31 & A & 3 \\
\hline 18 & A & 4 & 19 & $A$ & 4 & 30 & $A$ & 4 & 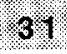 & $A$ & 4 \\
\hline 18 & 8 & 1 & 19 & $B$ & 1 & 30 & $B$ & 1 & 31 & $B$ & 1 \\
\hline 18 & $B$ & 2 & 189 & $\sqrt{B}$ & 28 & 30 & B & 2 & 31 & B & 2 \\
\hline 18 & $B$ & 3 & 19 & $B$ & 3 & 30 & 8 & 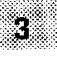 & 31 & B & 3 \\
\hline 18 & $B$ & 4 & 19 & $B$ & 4 & 30 & $B$ & 4 & 61 & $\mathrm{~B}$ & 4 \\
\hline 18 & 0 & 1. & 19 & $c$ & 1 & 30 & $c$ & 1 & 31 & $\mathrm{C}$ & 1 \\
\hline 18 & $c$ & 2 & 19 & 0 & 2 & 30 & C & 2 & 31 & C & 2 \\
\hline 18 & $\mathrm{C}$ & 3 & 19 & $\mathrm{C}$ & 3 & 30 & 9 & 3. & 31 & $\checkmark$ & 3 \\
\hline 18 & $\mathrm{C}$ & 4 & 19 & $\mathrm{C}$ & 4 & 30 & C & $A$ & 93 & ce & 4 \\
\hline 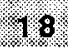 & (5) & 1 & 19 & $\mathrm{D}$ & 1 & 30 & $D$ & 1 & 31 & D & 1 \\
\hline 18 & $\mathrm{D}$ & 2 & 199 & $\sqrt{10}$ & 2. & 30 & $D$ & 2 & 31 & $U$ & 2 \\
\hline 18 & $D$ & 3 & 19 & $D$ & 3 & 30 & 9 & 3 & 31 & ת & 3 \\
\hline 18 & D & 4 & 19 & $\mathrm{D}$ & 4 & 30 & $\mathrm{D}$ & 4 & 311 & D & 4 \\
\hline
\end{tabular}

levels and to achieve a large enough sample so that the main effects in the experiment are estimated with equal standard errors. The fraction of the factorial design that would be necessary to develop a Latin Square is represented by the highlighted arcas in Fig 1.

In the Latin Square design, a series of single squares is created to address the multiple factors forming the experiment. In Table 1, a single square is represented by the length of the testing period or, in this case, a rotation. The factors in each rotation are material; tooth location for placement of the sample and the patient forming the experimental population. In designing the square, each factor has four levels, and therefore four rotations are necessary to complete the square. The number of squares can be expanded to an appropriate number to arrive at a reasonable $n$ to evaluate each factor and its four levels. In the design in Table 1, four patients each with four tooth locations will permit the evaluation of the wear resistance of 3 composite resins and an amalgam control material during four test periods or

Table 1. The Latin Square Experimental Design of Cluster Number 4

\begin{tabular}{|c|c|c|c|c|c|}
\hline Square & $\begin{array}{l}\text { Tooth } \\
\text { (No.) }\end{array}$ & Patient 1 & Patient 2 & Patient 3 & Patient 4 \\
\hline \multirow[t]{4}{*}{ Rotation 1} & 18 & Visio-Fil & Tytin & Ful-Fil & Sinter-Fil II \\
\hline & 19 & Sinter-Fil II & Visio-Fil & Tytin & Ful-Fil \\
\hline & 30 & Ful-Fil & Sinter-Fil II & Visio-Fil & Tytin \\
\hline & 31 & Tytin & Ful-Fil & Sinter-Fil II & Visio-Fil \\
\hline \multirow[t]{4}{*}{ Rotation 2} & 18 & Sinter-Fil II & Visio-Fil & Tytin & Ful-Fil \\
\hline & 19 & Ful-Fil & Sinter-Fil II & Visio-Fil & Tytin \\
\hline & 30 & Tytin & Ful-Fil & Sinter-Fil Il & Visio-Fil \\
\hline & 31 & Visio-Fil & Tytin & Ful-Fil & Sinter-Fil Il \\
\hline \multirow[t]{4}{*}{ Rotation 3} & 18 & Ful-Fil & Sinter-Fil II & Visio-Fil & Tytin \\
\hline & 19 & Tytin & Ful-Fil & Sinter-Fil II & Visio-Fil \\
\hline & 30 & Visio-Fil & Tytin & Ful-Fil & Sinter-Fil Il \\
\hline & 31 & Sinter-Fil II & Visio-Fil & Tytin & Ful-Fil \\
\hline \multirow[t]{4}{*}{ Rotation 4} & 18 & Tytin & Ful-Fil & Sinter-Fil Il & Visio-Fil \\
\hline & 19 & Visio-Fil & Tytin & Ful-Fil & Sinter-Fil Il \\
\hline & 30 & Sinter-Fil II & Visio-Fil & Iytin & Ful-Fil \\
\hline & 31 & Ful-Fil & Sinter-Fil II & Visio-Fil & Tytin \\
\hline
\end{tabular}


rotations. Each group of four patients was called a "patient cluster," and four clusters provided data to evaluate a total of 12 composite resins.

The Michigan Computer Graphics Coordinate Measuring System (MCGCMS) ${ }^{27,28}$ was selected as the measurement method for this study. The MCGCMS used a contact probe interfaced with a computer to digitize the surface of a composite sample in the $\mathrm{x}, \mathrm{y}$, and $\mathrm{z}$ axes. A sensitivity of $1 \mu \mathrm{m}$ and a reliability of $\pm 3 \mu \mathrm{m}$ was reported carlier for the MCGCMS. ${ }^{27}$

The patient population was the edentulous patient wcaring a spccially designed complete denture. The edentulous patient model was also reported in earlier articles ${ }^{27,28}$ as was the fabrication of the test prostheses and the advantages of this model system. The mandibular denture used in the evaluation of composite resin wear was designed with special posterior teeth serving as the carriers for the different materials under investigation. These special teeth could be removed from the denture base for direct measurements using the MCGCMS. Maxillary posterior denture teeth with the mesial lingual cusp cast in a chromium-cobalt alloy were articulated opposing the mandibular sample sites. These cast cusps were positioned to occlude against the test samples placed in the mandibular sample carriers. Material placement was completed after the dentures were processed and polished using an intraoral technique. In all instances, the manufacturers' recommended procedures were followed.

The denture patient was selected as the experimental population because of an increased number and range of occlusal contacts during chewing, clenching, and bruxing activities as compared with the dentate patient. In the patient with natural teeth, tooth contacts occur at and around the maximum intercuspal position, and any lateral or lateralprotrusive mandibular movements result in a separation of the posterior teeth by some anterior tooth guidances, thereby limiting both the range and area of occlusal contact of the posterior tceth. In the denture patient, these occlusal contacts are controlled in the development of the occlusion.

Four material placement sites were selectcd (tooth no. $18,19,30$, or 31 ) in the mandibular arch to determine if location influenced wear, and each material would be placed in each of the locations during a 3-month test period. Following initial randomized placement, each tcst sample was measured

Table 2. Composite Resin Materials and the Amalgam Alloy Studicd

\begin{tabular}{|c|c|c|c|}
\hline Material & Classification & Manufacturer & Batch Number \\
\hline Status & Fine particle & $\begin{array}{l}\text { Healthco International, Inc. } \\
\text { Boston, MA } 02116\end{array}$ & 0675083 \\
\hline Ful-Fil & Fine particle & $\begin{array}{l}\text { The L. D. Caulk Division } \\
\text { Dentsply International, Inc. } \\
\text { Milford, DE 19963-0359 }\end{array}$ & 0307881 \\
\hline Visio-Fil & Fine particle & $\begin{array}{l}\text { ESPE-Premier Sales Corp. } \\
\text { Norristown, PA } 19401\end{array}$ & 0014 \\
\hline $\mathrm{P}-30$ & Fine particle & $\begin{array}{l}\text { 3-M } \\
\text { St. Paul, MN } 55144\end{array}$ & $70-2004-8600-2$ \\
\hline Estilux Posterior & Fine particle & $\begin{array}{l}\text { Kulzer, Inc. } \\
\text { Irvine, CA } 92714\end{array}$ & 7183162 \\
\hline Bisfil I & Fine particle & $\begin{array}{l}\text { BISCO } \\
\text { Lombard, IL } 60148\end{array}$ & 062384 \\
\hline P-10 & Fine particle & $\begin{array}{l}\text { 3-M } \\
\text { St. Paul, MN } 55144\end{array}$ & 6194 \\
\hline Adaptic II & Hybrid/blend & $\begin{array}{l}J \& J \\
\text { E. Windsor, NJ } 08520\end{array}$ & $6 \mathrm{H} 5211$ \\
\hline Sinter-Fil II & Hybrid/blend & $\begin{array}{l}\text { Teledyne-Getz } \\
\text { Elk Grove Village, II, } 60007\end{array}$ & 012386 \\
\hline $\begin{array}{l}\text { Hcrculite Condensable } \\
\text { Distalite }\end{array}$ & $\begin{array}{l}\text { Hybrid/blend } \\
\text { Microfill }\end{array}$ & $\begin{array}{l}\text { Sybron/Kerr, Romulus, MI } \\
\text { J \& J } \\
\text { E. Windsor, NJ } 08520\end{array}$ & 28034 \\
\hline Heliomolar & Microfill & $\begin{array}{l}\text { Vivadent (USA), Inc. } \\
\text { Tonawanda, NY } 14150\end{array}$ & 780384 \\
\hline Tytin & Amalgam & $\begin{array}{l}\text { Kerr Manufacturing Co. } \\
\text { Romulus, MI } 48174\end{array}$ & \\
\hline
\end{tabular}

All compositc resins are light cured. 
using the MCGCMS. The materials remained in their respective tooth locations for the test period of 3 months. At the end of this test period, the patients were recalled and the test teeth were removed from the mandibular denture bases for direct sample measurements. Following the measurement session, the materials were removed from the four teeth, and new materials were placed in accordance with a rotational plan developed for each material and each paticnt in the Latin Square experimental design (Table 1). The experiment terminated when each matcrial was evaluated in all four tooth locations. All four clusters were managed in this manner to complete the evaluation of the 12 composite resins under investigation.

The 12 composite resins selected for this investigation are listed in Table 2. Their sclection was based on their published composite classifications types. ${ }^{29-31}$ The composites chosen included seven fine-particle composites (P-10 [3-M, St Paul, MN], Bisfil I [Bisco, Lombard, IL], Estilux Posterior [Kulzer, Inc, Irvine, CA], P-30 [3-M], Visio-Fil [ESPE-Premier Sales Corporation, Norristown, PA], Ful-Fil [L.D. Caulk Division, Dentsply International, Inc, Milford, DE], and Status [Healthco International, Inc, Boston, MA]), three blends (Herculite-Condensable [Sybron/Kerr, Romulus, MI], Sinter-Fil II [Teledyne-Getz, Elk Grove Village, IL], Adaptic II [J\&J, East Windsor, NJ]), and two microfilled composite resins (Heliomolar [Vivadent USA, Inc, Tonawanda, VY] and Distalite [J\&J]).
The site selected for wear measurement on the surface of each sample was an area of $4 \mathrm{~mm}^{2}$ at the point of maximum contact with the chromiumcobalt antagonist in the opposing arch. Data were collected by measuring the height of the $\mathrm{z}$ axis for 14,000 data points on the surface of the sample using an exactly located measurement matrix of $10-\mu \mathrm{m}$ intervals on the $x$ axis and $100-\mu \mathrm{m}$ intervals on the $y$ axis. Data collected at the beginning of the experiment and at the end of each 3-month test period provided the nceded information to compute the wear volume loss reported as $\mathrm{mm}^{3} / \mathrm{mm}^{2}$.

\section{Results}

The Latin Square experimental design provides investigators with an extremely powerful ANOVA statistical method. The Latin Square ANOVA and the F values for the single squares in each cluster, nos. 1 through 4, are presented in Table 3. Each single square, represcnted as a rotation in a cluster, was examined for the following factors: (1) material, (2) tooth location, and (3) the patient. For the single squares in Table 3 , material was found to be a main effect factor with $\mathbf{F}$ values greater than $6.59,5.41$, or 4.76 (error $d f=4,5$, or 6 , respectively) indicating a difference at the $5 \%$ level of significance.

To analyze the fourth factor of rotation, the data were pooled for the four rotation squares within each cluster nos. 1 through 4 , and as shown in Table 4,

Table 3. The Latin Square Analysis of Variance and the F Values for the Single Squares in Each Clustcr Numbers 1 Through 4

\begin{tabular}{|c|c|c|c|c|c|c|c|c|c|}
\hline \multirow{2}{*}{$\begin{array}{c}\text { Cluster } \\
\text { No. }\end{array}$} & \multirow[b]{2}{*}{ Square } & \multicolumn{8}{|c|}{ Source of Variation } \\
\hline & & Patient & $d f$ & Tooth & $d f$ & Material & $d f$ & Error* & $d f$ \\
\hline \multirow[t]{4}{*}{1} & Rotation 1 & 1.602 & 3 & 0.440 & 3 & 4.012 & 3 & 0.004 & 6 \\
\hline & Rotation 2 & 0.579 & 3 & 0.263 & 3 & $5.768 * *$ & 3 & 0.001 & 6 \\
\hline & Rotation 3 & 1.332 & 3 & 1.515 & 3 & $16.753^{* *}$ & 3 & 0.001 & 5 \\
\hline & Rotation 4 & 0.687 & 3 & 0.348 & 3 & $15.255^{* * *}$ & 3 & 0.000 & 6 \\
\hline \multirow[t]{4}{*}{2} & Rotation 1 & 2.083 & 3 & 0.734 & 3 & $10.451^{* * *}$ & 3 & 0.001 & 6 \\
\hline & Rotation 2 & 0.599 & 3 & 0.939 & 3 & $11.785^{* * *}$ & 3 & 0.001 & 6 \\
\hline & Rotation 3 & $5.891 * *$ & 3 & 2.631 & 3 & $14.787^{* * *}$ & 3 & 0.000 & 5 \\
\hline & Rotation 4 & 4.928 & 3 & 1.538 & 3 & $9.139 * *$ & 3 & 0.001 & 5 \\
\hline \multirow[t]{4}{*}{3} & Rotation 1 & 0.210 & 3 & 0.623 & 3 & $7.889 * *$ & 3 & 0.000 & 4 \\
\hline & Rotation 2 & 0.676 & 3 & 0.564 & 3 & $7.386 * * *$ & 3 & 0.000 & 6 \\
\hline & Rotation 3 & 0.883 & 3 & 0.515 & 3 & $5.898 * *$ & 3 & 0.000 & 6 \\
\hline & Rotation 4 & 0.146 & 3 & 0.005 & 3 & 4.067 & 3 & 0.000 & 6 \\
\hline \multirow[t]{4}{*}{4} & Rotation 1 & 2.674 & 3 & 0.246 & 3 & $9.080^{* * *}$ & 3 & 0.001 & 6 \\
\hline & Rotation 2 & 1.547 & 3 & 0.836 & 3 & $13.337^{* * *}$ & 3 & 0.000 & 6 \\
\hline & Rotation 3 & 2.326 & 3 & 0.418 & 3 & $14.531 * *$ & 3 & 0.001 & 5 \\
\hline & Rotation 4 & 2.495 & 3 & 0.534 & 3 & $5.018 * *$ & 3 & 0.002 & 6 \\
\hline
\end{tabular}


Table 4. The Latin Square Analysis of Variance and the F Values for the Pooled Squares in Each Clustcr Numbers 1 Through 4

\begin{tabular}{ccccccccccc}
\hline \multirow{2}{*}{$\begin{array}{c}\text { Cluster } \\
\text { No. }\end{array}$} & Patient & $d f$ & Tooth & df & Material & $d f$ & Rotation & $d f$ & Error & $d f$ \\
\hline 1 & 0.738 & 3 & 1.209 & 3 & $23.024^{* *}$ & 3 & 1.538 & 3 & 0.002 & 23 \\
2 & 1.026 & 3 & 0.483 & 3 & $29.497^{* *}$ & 3 & 2.287 & 3 & 0.001 & 22 \\
3 & 0.498 & 3 & 0.507 & 3 & $20.792^{* *}$ & 3 & 1.706 & 3 & 0.001 & 22 \\
4 & 2.848 & 3 & 0.034 & 3 & $31.048^{* *}$ & 3 & 2.673 & 3 & 0.001 & 23 \\
\hline
\end{tabular}

* Mean square in $\mathrm{mm}^{2} / \mathrm{mm}^{3}$.

* Statistically different at the $5 \%$ level of significance, when $\mathrm{F} \geq \mathrm{F}[d f=3, d f=22]=3.05$ and $\mathrm{F} \geq \mathrm{F}[d f=3, d f=23]=3.03$

material was found a main effect factor with $\mathrm{F}$ values greater than 3.05 or 3.03 (error $d f=22$ or 23 , respectively) indicating a difference at the $5 \%$ level of significance.

When all of the squares for the 16 patients in cluster nos. 1 through 4 were pooled, the Latin Squarc ANOVA again showed that material was a main effect factor with $F$ values above 2.71 or 2.03 (subject $d f=3$ or 9 , respectively) indicating a difference at the $5 \%$ level of significance (Table 5 ).

The ANOVA for the amalgam control material, when all of the squares for the 16 patients in cluster nos. 1 through 4 were pooled, showed that none of the factors of amalgam (grouped by the different clusters), rotation, tooth location, or patient had differences at the $5 \%$ level of significance (Table 6). In the absence of significant differences for amalgam between the different clusters, all the amalgam data were grouped as one control. Recognizing that material was the only main effect factor among tooth location, patient, and rotation with a difference at the $5 \%$ level of significance, the in vivo mean wear volume loss for the 12 composite resins, and the amalgam control and their confidence intervals with 95\% probability using the $t$ distribution were determined and are reported in Table 7.

Table 5. The Latin Square Analysis of Variance and the F Values for the Pooled Squares in All Cluster Numbers 1 Through 4

\begin{tabular}{lcccl}
\hline $\begin{array}{l}\text { Source of } \\
\text { Variation }\end{array}$ & $\begin{array}{c}\text { Sum of } \\
\text { Square* }\end{array}$ & df & $\begin{array}{c}\text { Mean } \\
\text { Square* }\end{array}$ & \multicolumn{1}{c}{$F$} \\
\hline Tooth & 0.006 & 3 & 0.002 & 1.639 \\
Material & 0.044 & $9^{* *}$ & 0.005 & $3.720^{* * * *}$ \\
Patient & 0.014 & $9^{* *}$ & 0.002 & 1.207 \\
Rotation & 0.007 & $3^{* *}$ & 0.002 & 1.759 \\
Cluster & 0.012 & 3 & 0.001 & 1.025 \\
Error & $\mathbf{0 . 1 1 7}$ & 90 & 0.001 & \\
\hline
\end{tabular}

* Sum of square and mean square in $\mathrm{mm}^{3} / \mathrm{mm}^{2}$.

**Degrees of freedom of material (or patirnt) cluster.

*** Statistically different at the $5 \%$ level of significance, when $\mathrm{F} \geq$ $\mathrm{F}[d f=3, d f=90]=2.71$ and $\mathbf{F} \geq \mathbf{F}[d f=9, d f=90]=2.03$.
In Table 7, the composite resins are ranked from the most to the least wear by mean wear volume loss in $\mathrm{mm}^{3} / \mathrm{mm}^{2}$.

\section{Discussion}

In this investigation, 16 patients were used to form four clusters using, the Latin Square experimental design to evaluate 12 composite resins and an amalgam control for the factors of rotation, material, location, and the patient.

The analyses of the factors of material, location, and the patient are presented in Table 3 where the factor rotation formed the single squares. In Table 3 , material was the main effect factor in most of the rotation single squares with the exception in cluster no. 1, rotation no. 1 where material was not the main effect factor $(\mathrm{F}=4.012<\mathrm{F}[d f=3, d f=6]=4.76)$. Similarly, in cluster no. 2 , rotation no. 3 , the matcrial was also not a main effect factor $(\mathrm{F}=5.891>\mathrm{F}$ $[d f=3, d f=5]=5.41$ ). The final square in Table 3, showing that material was not a main effect factor, was in cluster no. 3 , rotation no. $4(\mathrm{~F}=4.067<\mathrm{F}$ $[d f=3, d f=6]=4.76)$.

Table 6. The Analysis of Variance and the $F$ Values for the Amalgam Control in All Cluster Numbers 1 Through 4

\begin{tabular}{lcrcc}
\hline $\begin{array}{c}\text { Source of } \\
\text { Variation }\end{array}$ & $\begin{array}{c}\text { Sum of } \\
\text { Square* }\end{array}$ & df & $\begin{array}{c}\text { Mean } \\
\text { Square* }\end{array}$ & $F^{* *}$ \\
\hline Cluster & 0.0002 & 3 & 0.0001 & 0.6253 \\
Material*** & 0.0002 & 3 & 0.0001 & 0.5369 \\
Tooth & 0.0005 & 3 & 0.0002 & 1.1782 \\
Patient & 0.0022 & 15 & 0.0001 & 1.1569 \\
Frror & 0.0052 & 37 & 0.0001 & \\
Sum & 0.0081 & 61 & 0.0001 & \\
\hline
\end{tabular}

*Sum of square and mean square in $\mathrm{mm}^{3} / \mathrm{mm}^{2}$.

**Statistically different at the $5 \%$ level of significance, when $F \geq F$ $(d f=3, d f=37) \approx 2.84$ and $\mathbf{F} \geq \mathbf{F}(d f=15, d f=37) \approx 2.00$.

***The source of variation of matcrial which consists of the amalgam control in each cluster was also the source of variation of rotation. 
Table 7. The In Vivo Mean Wear Volume Loss and Their Confidence Interval for the 12 Composite Resins and Amalgam Control in $\mathrm{mm}^{3} / \mathrm{mm}^{2}$

\begin{tabular}{llll}
\hline \multicolumn{1}{c}{ Materials } & $n$ & Mean & Confidence Interval $^{*}$ \\
\hline P-10 & 16 & 0.140 & $0.121 \leq \mathrm{m} \leq 0.158$ \\
Estilux Post. & 16 & 0.140 & $0.121 \leq \mathrm{m} \leq 0.158$ \\
Visio-Fil & 16 & 0.130 & $0.112 \leq \mathrm{m} \leq 0.148$ \\
Heliomolar & 16 & 0.120 & $0.102 \leq \mathrm{m} \leq 0.139$ \\
Distalite & 15 & 0.118 & $0.099 \leq \mathrm{m} \leq 0.137$ \\
Adaptic II & 16 & 0.114 & $0.096 \leq \mathrm{m} \leq 0.133$ \\
Status & 16 & 0.109 & $0.091 \leq \mathrm{m} \leq 0.128$ \\
Ful-Fi] & 16 & 0.102 & $0.083 \leq \mathrm{m} \leq 0.120$ \\
Herculite-Cond. & 15 & 0.099 & $0.080 \leq \mathrm{m} \leq 0.118$ \\
P-30 & 15 & 0.097 & $0.078 \leq \mathrm{m} \leq 0.116$ \\
Sinterfil II & 15 & 0.092 & $0.073 \leq \mathrm{m} \leq 0.111$ \\
Bisfil I & 16 & 0.087 & $0.069 \leq \mathrm{m} \leq 0.106$ \\
Tytin & 62 & 0.028 & $0.022 \leq \mathrm{m} \leq 0.033$ \\
\hline
\end{tabular}

*Confidence interval at $95 \%$ probability ( $t$ distribution).

To determine the effect of the factor of rotation, it is necessary to pool the data from the four rotation squares as a cluster and to subject this combined data to the Latin Square ANOVA. Equally important in the support of this combining process are the errors of the mean of squares in Table 3. If the difference between the treatment means in each square is fairly comparable from square to square, we may combine the sums of squares and their corresponding degrees of freedom to obtain the estimate of experimental error. ${ }^{24}$ In Table 3 , the errors of the mean of the squares in all four clustcrs ranged between 0.000 to $0.004 \mathrm{~mm}^{3} / \mathrm{mm}^{2}$, meaning that the experimental design was under control and combining of the squares was appropriate.

In Table 4, the rotation squares were pooled for the Iatin Square ANOVA for each clustcr nos. 1 through 4. The $\mathbf{F}$ values for patient, tooth, material, and rotation in Table 4 showed that in all four clusters, only material among the four factors was a main effect variable, with differences in the wear volume loss at the $5 \%$ level of significance. The error of the mean of squares in Table 4 again supports the further combining of the data from all four clusters.

In Table 5, the Latin Square ANOVA of the pooled data from all 16 squares in the four clusters showed again that material was a main effect variable, with differences in the wear volume loss at the $5 \%$ level of significance. All other factors, including the clustcrs, were not significantly different. It is important to realize that with the Latin Square analysis, the degree of freedom in the computations is quite different than the standard ANOVA. In Table 5, the degrees of freedom for the factor's tooth, rotation, and cluster are all 3 , or $n_{1}-1$ where $n$ is the number of squares in a cluster. However, the degrees of freedom for the factor's material and the patients are 9 , which was detcrmined by the formula $d f=\left(\mathrm{n}_{1}-1\right) \cdot\left(\mathrm{n}_{2}-1\right)=9$. In this case, $n_{1}$ is the cluster, and $n_{2}$ is the materials within the cluster. Similarly, $n_{2}$ could equal the patients within the cluster in the evaluation of that factor's effect. It must be remembered that the amalgam was the control material in each cluster, and in the Latin Square analysis amalgam was treated as a different material in each cluster. To detcrmine that the amalgam materials were not the influencing material in the analysis, the amalgam wear data were subjected to a separate ANOVA.

In Table 6 , the ANOVA and the F values for the amalgam in all squares for all cluster nos. 1 through 4 showed no significant differences for matcrial, tooth, patient, rotation, or clustcr. Therefore, this leads to the conclusion that amalgam was not influencing the factor material, but rather it was the other 12 composite resins.

Examination of the mean wear volume loss for the 12 composite resins in Table 7 clearly points out that none of these materials came close to the amalgam for wear resistance. The amalgam during the 3-month test periods experienced a mean wear volume loss of $0.028 \mathrm{~mm}^{3} / \mathrm{mm}^{2}$. The wear volume loss was $0.087 \mathrm{~mm}^{3} / \mathrm{mm}^{2}$ or greater for all of the composite resins examined or more than a $200 \%$ increase in wear. Equally important in this study was the amount of wear that occurred during the 3-month test periods using the denture patient in the experimental method. A mean volume loss of $0.028 \mathrm{~mm}^{3} /$ $\mathrm{mm}^{2}$ for the amalgam and $0.087 \mathrm{~mm}^{3} / \mathrm{mm}^{2}$ or greater for all the composites studied was certainly of a large enough magnitude to limit the test period to 3 months and supported the choice of the patient population. The ability of the MCGCMS to consistently measure the wear with precision and accuracy was another important advantage of the experimental design.

In an earlier study, ${ }^{32}$ the volume percentage of the filler particle content for each of the 12 composite materials had been determined, and in an attempt to add more information to the explanation of the results in this project, the volume pcrcentage was plotted along with the mean wear volume loss for the 12 composite resins (Fig 2). The selection of the materials for this study was based on the published composite classification information that would suggest their filler particle content. Therefore, it seemed 


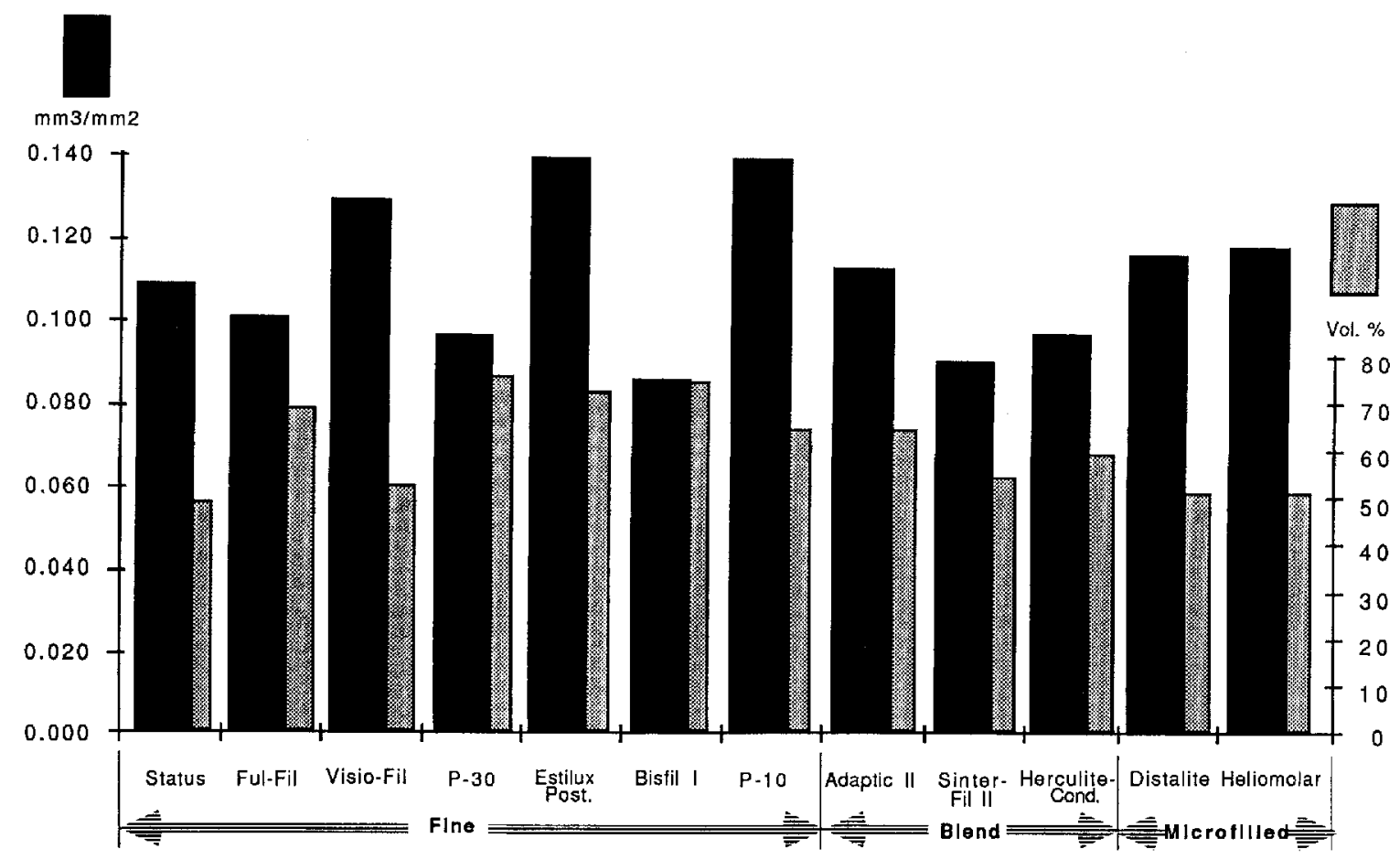

Figure 2. Mean wear volume loss and volume percentage of filler particles in the 12 composite resins plotted according to their classification by type (eg, fine particle, blends, and microfilled).

appropriate to include this information on the volume percentage of filler particles in each of the 12 materials to substantiate their classifications as microfilled, blends, and fine-particle composites and to determine if any correlations existed between the filler particle and wear. It is interesting to note in Figure 2, when the composite resins were rank ordered, that a trend could not be found between wear volume loss and the published composite classification type for the 12 materials. In fact, a regression analysis comparing the volume percentage filler and wear volume loss produced a correlation coefficient, $r=-0.158$, which was not significant at the $95 \%$ level.

It has been suggested that filler content, particularly the size of filler particle within a composite resin formulation, has the potential to influence the wear performance of a composite resin..$^{28,31-35}$ It has been reported that the greater the size of the particle, the greater the potential for wear. ${ }^{28}$ If this is true, it would seem reasonable to expect a trend to appear in the wear resistance of the composites studied.

In Figure 2, clearly the volume percentage filler and the composite classification type within and between composite types are very different. The absence of any relationship between mean volume loss and the volume percentage filler was confirmed by the correlation coefficient $r=-0.158$. Perhaps the absence of any trends can also be related to the lack of sensitivity in the current classification systems; ie, fine-particle, blends, and microfilled composites, to clearly show differences in filler particle content between materials in each type. It should also be stated that the published information about the classification type of a composite resin may not be the most accurate information to use in selecting composites based on their filler particle composition. Equally important in this discussion is the attempt to examine the hypothesis that composites with larger particles would experience more wear, or for that matter, the examination of any other hypothesis on cause-effect relationships, using commercially available composites. There are simply too many uncontrolled variables and obvious other formulation considerations in commercially available products that are influencing factors in the mechanisms of wear. Most probably, all of these previous reasons have contributed significantly to the results in this investigation.

If improvements are to bc made in the wear resistance of composite resins and if ultimately they are to be universally accepted as restorative materials in dentistry, then in vitro and in vivo cxperiments will be required using materials with controlled 
formulations, for example, the filler particle content to examine its role in wear. Without such experiments, clinical trials will continue to be more "product" oriented in their evaluations and add very little significant knowledge to the understanding of the wear process itself and the material sciences.

\section{Conclusions}

Within the limitations of the present investigation the following conclusions can be drawn.

1. The validity of the Latin Square experimental design was shown from an ANOVA with the factor of material being statistically different at the $5 \%$ level of significance.

2. Significant differences for mean wear volume loss were found between all composite resins studied and the amalgam control $(P=0.001)$, with wear in $\mathrm{mm}^{3} / \mathrm{mm}^{2}$ being $200 \%$ or greater for the composite resins when compared with the amalgam.

3. The ranking of the commercially available composite resin materials from least to most wear was determined; however a relationship between their published composite classification types and wear volume loss in $\mathrm{mm}^{3} / \mathrm{mm}^{2}$ was not evident.

4. The absence of any relationship between mean wear volume loss and the volume percentage filler was confirmed by the correlation coefficient $\mathrm{r}=$ -0.158 .

\section{Acknowledgments}

The authors acknowledge the contributions during this project of Dr Masood Tirgari and Dr Richard G. Whitney, and Cathy A. Russo.

\section{References}

1. Roule1 JF: Degradation of Dental Polymers. Basel, Karger, 1987

2. Sulong ZA, Aziz RA: Wear of matcrials used in dentistry: A review of the litcrature. J Prosthet Dent 1990;63:342-349

3. Bryant RW: Posterior composite resin restorations - A review of clinical problems. Aust Prosthodont J 1987;1:41-50

4. Cvar JF, Ryge G: Criteria for the clinical evaluation of dental restorative materials, US Public Health Scrvice publication No. 790-244. San Francisco, CA, US Government Printing Office, 1971

5. Crumpler DC, Heymann HO, Shugars DA, et al: Five-year clinical investigation of one conventional composite and three microfilled resins in anterior teeth. Dent Mater 1988;4:217222
6. Gerbo LR, Mueningoff LM, Leinfelder KF, et al: A comparative evaluation of optical standards for measuring wear IADR Abstract 141\}.J Dent Res 1990;69:126

7. Taylor DF, Bayne SC, Sturdevant JR, et al: Vivadent comparison to M-L Leinfelder, and USPHS clinical wear scales $\{\mathrm{IADR}$ Abstrac1 416\}.J Dent Res 1990;69:160

8. Leinfelder KF, Taylor DF, Barkmeier WW, et al: Quantitative wear measurement of posterior composite resins. Dent Mater $1986 ; 2: 198-201$

9. Abell AK, Leinfelder KF, Turner DT: Microscopic observations of the wear of a tooth restorative composite in vivo. J Biomed Mat Res 1983;17:501-507

10. Lutz F, Phillips RW, Roulet JF, et al: In vivo and in vitro wear of potential posterior composites. J Dent Res 1984;63:914-920

11. Hirt TH, Lutz F, Roulet JF: In vivo evaluation of occlusal wear of two experimental composites versus amalgam. J Oral Rehabil 1984;11:511-520

12. Hengchang XU, Tong $W$, shiging S: Wear patterns of composite restorative, resins in vivo; observations by scanning electron microscopy. J Oral Rchabil 1985;12:389-400

13. White $\mathrm{KC}$, Leinfelder $\mathrm{KF}$, Russell CM: An in vivo technique for measuring wear of denture teeth $\{$ IADR Abstract 129\}. J Dent Res 1990;69:125

14. Larsen IB, De Chiffre L, Asmussen F: A new method for measuring wear of Restorations in vivo [LADR Abstract 138 $\mid$.J Dent Res 1990;69:126

15. Mitchem JC, Gronas DG: The use of dentures for the evaluation of the abrasive wear of composites [IADR Abstract 142. J Dent Res 1990;69:126

16. Mitchem JC, Gronas DG: The continued in vivo evaluation of the wear of restorative resins. J Am Dent Assoc 1985;111:961964

17. DeLong R, Pintado M, Douglas WH: Measurement of change in surface contour by compuler graphics. Dent Mater 1985;1: $27-30$

18. Roulet JF, Reich TH, Lutz F: High precision ocd lusal mapping: A new method for measuring wear of posterior composites [AADR Abstract 457].J Dent Res 1983;62:220

19. Atkinson JT, Gloves D, Lacor MJ, et al: The measurement of wear in dental restorations using laser dual-source contouring. Wear 1982;76:91-104

20. Lambrechts P, Vuylsteke M, Vanherle G, et al: Quantitative evaluation of the wear resistance of posterior dental restorations. A new three-dimensional measuring technique. J Dent $1984 ; 12: 252-267$

21. Braem M, Lambrechts $P$, Van Doren $V$, et al: In vivo evaluation of four posterior composites: Quantitative wear measurements and clinical behavior. Dent Mater 1986;2:106113

22. Dixon WJ, Massey FJ Jr: Introduction to Statistical Analysis (ed 3). New York, NY, McGraw-Hill, 1969 p 310

23. Koltz S, Johnson NL: Latin squares, in Koltz $\mathrm{S}$, Johnson NL (eds): Encyclopedia of Statistical Science. Wiley, New York, NY, 1983, pp 504-509

24. Edwards AL: Experimental design in psychological research. New York, NY, Holt, Rinehart and Winston, 1965, pp 259-264

25. Winer BJ: Statistical principles in experimental design. New York, NY, McGraw-Hill, 1962, p 524-538

26. Lang BR, Bloem TJ, Wang RF, et al: An in-vivo experiment to test composite resin wear using the Latin-Square analysis. Int J Prosthodont 1991;4:529-538 
27. McDowell GC, Bloem TJ, Lang BR, et al: In-vivo wear. Part I: The Michigan Computer Graphics Measuring System. J Prosthet Dent 1988;60:112-120

28. Bloem TJ, McDowell GG, Lang BR, et al: In-vivo wear. Part II: Wear and abrasion of composite restorative materials. J Prosthet Dent 1988; 60:242-248

29. Leinfelder KF: Composite resins: Properties and clinical performance in O'Brien WJ (ed): Dental Materials: Properties and Selection. Chicago, IL, Quintessence, 1989, pp 139157

30. Farah JW, Powers JM: Anterior and posterior composites. The Dental Advisor 1984;1:5

31. Farah JW, Powers JM: Rating posterior composites. The Dental Advisor 1986;3:4

32. Jaarda MJ, Lang BR, Wang RF, et al: Measurement of composite resin filler particles using scanning elcctron microscopy and digital imaging.J Prosthet Dent 1991 (in press)
33. Roulet JF: Degradation of dental polymers. New York, NY, Karger, 1987

34. Roulet JF: A materials scientist's view: Assessment of wear and marginal integrity. Quintessence Int 1987;18:543-552

35. Leinfelder KF: Wear patterns and rates of posterior composite resins. Int Dent J 1987;37:152-157

36. Swift EJ Jr: Wear of composite resins in permanent posterior teeth. J Am Dent Assoc 1987;115:584-588

37. Bryant RW: Posterior composite resin restorations-A review of clinical problems. Aust Prosthodont J 1987:41-50

38. Lcinfelder KF: Composite resins: Properties and clinical performance in O'Brien WJ (cd): Dental Materials: Properties and Selection. Chicago, IL, Quintessence, 1989, pp 139 . 157

39. Leinfelder KF: Using composite resin as a posterior restorative material.J Am Dent Assoc 1991;122:65 